\title{
Bullying and Victimization Among School-age Children: Stability and Links to Proactive and Reactive Aggression
}

\author{
Marina Camodeca, Free University, and Pedological Institute, \\ Amsterdam, The Netherlands, Frits A. Goossens, \\ Mark Meerum Terwogt and Carlo Schuengel, Free University, \\ Amsterdam, The Netherlands
}

\begin{abstract}
The main aim of the study relates to the links between bullying and victimization on the one hand and reactive and proactive aggression on the other. In addition, we also investigated stability and incidence of bullying and victimization. At age 7, 236 children were rated on bullying and victimization using peer reports. At age 8, 242 children were rated again. Two hundred and fifteen children (114 girls and 101 boys) were present at both time points. Reactive and proactive aggression was assessed by teachers. The results showed that bullies and bully/victims were both reactively and proactively aggressive, while victims were only reactively aggressive. A moderate degree of stability of bullying and victimization was found, with bullying being more stable than victimization. Boys were more often bullies than girls and more stable than girls in victimization. Stable victims and stable bully/victims were more reactively aggressive than their unstable counterparts. The relevance of the outcomes to preventing future maladjustment and suggestions for further research are discussed.
\end{abstract}

Keywords: bullying; victimization; proactive aggression; reactive aggression

One of the first authors to define bullying was Olweus, who wrote that 'a person is being bullied when he or she is exposed, repeatedly and over time, to negative actions on the part of one or more other persons' (Olweus, 1991, p. 413). Such negative actions may be physical, verbal or psychological, they are intentional in nature, and usually involve a real or perceived imbalance in strength/power. Bullying is a social phenomenon and takes place in a relatively permanent group (such as a school class), in which victims have few opportunities to avoid their tormentors and the bully often gets support from other group members. In other words, their roles become defined (Salmivalli, Lagerspetz, Björkqvist, Österman, \& Kaukiainen, 1996).

It has been demonstrated that involvement in bullying is associated with social maladjustment in both victims and bullies. The former may suffer short-term emotional

Correspondence concerning this article and requests for reprints should be addressed to Marina Camodeca, Faculty of Psychology and Education, Free University, van der Boechorststraat 1, 1081 BT, Amsterdam, The Netherlands. Email:M.Camodeca@psy.vu.nl 
imbalances, such as lower self-esteem, higher levels of depression and negative appraisal of interpersonal competence (Hawker \& Boulton, 2000). In the longer term, there is a risk of social withdrawal in adulthood. Bullies, on the other hand, have been found to have behavior problems of an externalizing nature, such as truancy, dropping out of school, delinquency, violence or alcohol abuse (Loeber \& Dishion, 1983). Both bullying and victimization have been linked to relationship problems in adult life (Gilmartin, 1987; Rigby, Black, \& Wish, 1994). In short, social maladjustment is common in both bullies and victims.

The main aim of the present study was to examine the classification of children as bullies, victims, or bully/victims and to determine whether two types of aggression (reactive and proactive) were differentially related to children's role in bullying. Reactive aggression is a defensive response to provocation or trouble and is accompanied by anger, while proactive aggression is a goal-directed, deliberate, and cold-blooded action, which does not need any stimulus (Crick \& Dodge, 1996; Dodge, 1991; Dodge \& Coie, 1987). This may take the form of instrumental aggression ('object-oriented', aimed at obtaining an object or a privilege) or of bullying ('person-directed', used to intimidate or dominate a peer; Price \& Dodge, 1989). Crick and Dodge (1999) and Price and Dodge (1989) advanced the hypothesis that bullies would be more likely to demonstrate proactive aggression, while Pellegrini, Bartini and Brooks (1999) and Pulkkinen (1996) claimed that bullies may display both types of aggression. Thus, according to the latter authors, bullies are more likely to be pervasively aggressive. Kochenderfer and Ladd (1997) found their stable victims to be characterized by reactive aggression (see also Olweus, 1993; Schwartz, McFayden-Ketchum, Dodge, Pettit, \& Bates, 1998). Recently, Salmivalli and Nieminen (2002) have found that bully/ victims are the most proactively and reactively aggressive group, followed by bullies. Victims were more reactively aggressive than those uninvolved.

Although reactive and proactive aggression have been found to be strongly linked in almost all the studies on the topic, the distinction between them appears to be both reliable and valid. We explored whether being bullies, bully/victims or victims was linked to different types of aggression. Bullies and bully/victims were expected to be both proactively and reactively aggressive whereas victims were expected to be only reactively aggressive.

A longitudinal test-retest design was used. In this way, stable bullies, stable bully/victims and stable victims could be compared with the unstable ones, in terms of reactive and proactive aggression. The reason for this comparison is that in the literature we find that those who 'desist' in bullying or in being bullied show better adjustment than those who 'persist' (Loeber \& LeBlanc, 1990). Thus, the desisters may not have the same characteristics as the persisters. Kochenderfer and Ladd (1997) found that stable victims (boys) were more reactively aggressive than the unstable ones. Our purpose was to verify their findings in our sample, using different measures, and including bullies and bully/victims. Stable bullies and bully/victims were expected to be more proactively and reactively aggressive than those who were unstable, while stable victims were expected to be more reactively aggressive than the unstable ones.

A second goal was to investigate the stability of involvement in bullying (either as a bully, victim or bully/victim) over a period of one year. Gender differences were also explored. Olweus (1979) in his review of 16 studies found aggressive behavior to be very stable, especially over short intervals and when the participants were older. The short-term stability of victimization and bullying, within and across the school year, 


\section{Marina Camodeca et al.}

was also found by Kochenderfer and Ladd (1996a, 1997) and Boulton and Smith (1994). A fairly high stability also emerged from studies employing a longer period between assessments (Kumpulainen, Räsänen, \& Henttonen, 1999; Perry, Kusel, \& Perry, 1988; Pulkkinen \& Pitkänen, 1993; Salmivalli, Lappalainen, \& Lagerspetz, 1998; Sourander, Helstelä, Helenius, \& Piha, 2000). These results are all the more impressive if we take into consideration the fact that in the different studies a variety of measures (self-reports, peer reports and teacher reports) have been employed, and that stability has been found for subjects of different ages, irrespective of the period between assessments, which in one case was 8 years (Sourander et al., 2000). Two other issues arise here. The first is whether bullying is more stable than victimization, and the second is whether the stability of involvement in bullying is higher for boys than for girls. On both these issues the results have been inconsistent, with some authors finding that victimization is more stable (Sourander et al., 2000), some that bullying and victimization are equally stable (Boulton \& Smith, 1994), and some that bullying is more stable (Salmivalli et al., 1998). As to gender differences, the results are somewhat more consistent, with most studies indicating that the stability of involvement in bullying is greater for boys than for girls (Boulton \& Smith, 1994; Kumpulainen et al., 1999; Salmivalli et al., 1998; Sourander et al., 2000). However, while Sourander et al. (2000) claimed this greater stability for boys both for bullying and victimization, Boulton and Smith (1994) reported this only for victimization, and Salmivalli et al. (1998) reported this only for bullying. Pulkkinen and Pitkänen (1993) did not find any sex differences in relation to stability of aggression. In the present study, involvement in bullying was expected to be stable, although no hypotheses were made as to whether this stability was the same for bullying and victimization. Boys were expected to be more stably involved than girls.

Finally, the last aim of this study was to estimate the incidence of bullying and victimization among school-age children with reference to gender. Although there have been some studies into the prevalence of bullying in The Netherlands (Bokhorst, Goossens, Dekker, \& De Ruijter, 2000; Haselager, 1997; Mooij, 1992), neither the age of the samples employed nor the measures used to assess prevalence were comparable to our study. All of the above-mentioned Dutch studies have relied on Olweus' (1989) self-report Bully/Victim Questionnaire. The sample of Bokhorst et al. (2000) was roughly of the same age as the children in our study, but those of Haselager and Mooij were both older, and bullying usually decreases with age (Boulton \& Underwood, 1992; Olweus, 1991; Smith, Madsen, \& Moody, 1999; Whitney \& Smith, 1993). In addition to age effects, gender differences have been found (Boulton \& Underwood, 1992; Kochenderfer \& Ladd, 1996b; Lagerspetz, Björkqvist, Berts, \& King, 1982; Olweus, 1993; Whitney \& Smith, 1993). Boys have more often been found to be bullies than girls, although the more subtle ways of bullying employed by girls (damaging someone's reputation, refusing friendship, isolating the victim, instead of direct physical and verbal aggression) may be more difficult to detect (Björkqvist, Lagerspetz, \& Kaukiainen, 1992; Crick \& Bigbee, 1998; Crick \& Grotpeter, 1995; Olweus, 1993). In this study, too, boys were expected to be more often involved as bullies. No hypotheses were formulated regarding sex differences in victimization.

To sum up, the main interest was the relationship between bullying and victimization on the one hand and reactive and proactive aggression on the other. By collecting data at two points in time, it was also possible to compare the proactive and reactive aggression of stable bullies, stable victims and stable bully/victims with those who were not stably involved. Also the stability of involvement in bullying across a 
one-year period was investigated, and some data on the prevalence of bullying were supplied.

\section{Method}

\section{Sample}

The present work is part of a longitudinal study carried out in four schools in The Netherlands. It was conducted over an interval of one year with measurements at two points in time (T1 and T2). At T1 236 pupils (126 girls and 110 boys), from ten classes, took part. They attended third and fourth grade. In the following year there were 242 children (126 girls and 116 boys), from nine classes, attending fourth and fifth grade. Two classes from T1 merged into one at T2. The average age of the children ranged from 91.4 months $(\mathrm{SD}=9.0)$ at $\mathrm{T} 1$ to 105 months $(\mathrm{SD}=8.3)$ at $\mathrm{T} 2$.

Two hundred and fifteen children $(91.1 \%, 47 \%$ boys and $53 \%$ girls) remained in the study from the beginning to the end. Two of them changed classes due to grade retention; all the others remained in the same class. The composition of the classes changed only a little, either because children moved away or because new children moved into the vicinity of one of the participating schools. All the schools served a population of widely varying socioeconomic backgrounds, but predominantly of middle socioeconomic status. In order to enlist participants, all parents received a letter explaining the purpose of the study, the procedures involved, and the longitudinal nature of the project. Parental consent was obtained for more than $90 \%$ of the pupils approached, and parents agreed in $100 \%$ of the cases that their children-even if not participating-would be allowed to serve as informants to answer questions about bullying in the classroom. This relatively high rate of consent may have been prompted by the support given by the school principals to the study.

\section{Procedure}

Data were collected in the spring of 1998 and 1999. Pupils were requested to answer the Aggression and Victimization Scale at T1 and T2, while teachers filled in the Proactive and Reactive Scale only at T2. The analyses concerning stability were based on the 215 children present at both points in time, while the link between involvement in bullying and two types of aggression, being tested only at T2, was investigated for the whole sample present at T2.

Testing of the pupils took place individually in a quiet room in the school. Children were told it was best not to discuss what had been said, and that the information they supplied would be treated as confidential.

\section{Measures}

The Aggression and Victimization Scale (AVS). The Aggression and Victimization Scale was developed by Perry et al. (1988). The original version consists of 26 items: 7 aggression items (originally in the Peer Nomination Inventory by Wiggins and Winder, 1961), 7 victimization items (composed by the authors) and 12 filler items. Pupils were requested to nominate same-sex peers who fitted the behavior described in each item, excluding themselves from the list. Peers were chosen because they have access to group dynamics and rumors, which is often denied to teachers. Moreover, 
peer estimates are based on the judgements of a greater number of children and thus make possible aggregated measurement, which is not influenced by social desirability as self-reports may be.

The original version of the AVS was reduced by removing six of the 12 filler items and two aggression items which pointed more to aggression in general rather than to bullying or harassing others. Thus, an item like 'When he doesn't get his way he gets really mad' was removed, while an item like 'He makes fun of people' was kept. (An example of a victimization item is: 'Kids do mean things to him'.) We factor-analyzed (PCA) the 12 items for bullying and victimization and, after a varimax rotation, obtained the following psychometric figures: the loadings ranged from .77 to .87 (bullying at T1), from .60 to .85 (victimization at T1), from .74 to .91 (bullying at T2), from .68 to .89 (victimization at T2), while the total variance explained by the two factors was 66.8 at $\mathrm{T} 1$ and 75.6 at T2. The reliabilities were high at both points in time: at T1 alpha coefficients were .90 for bullying and .89 for victimization. At T2 the Cronbach's alphas were .93 and .92 for the two scales respectively.

We divided the scores by $n-1$, where $n$ is the number of same-sex children in each class: it is diminished by one because children did not nominate themselves. Although these scores are based only on nominations from same-sex peers, this is justified because boys and girls have been found to be in agreement about who the bullies and victims are (Boulton, 1999).

At both $\mathrm{T} 1$ and at T2, children were divided into four categories in order to have nominal scores. The 85th percentile of the bullying and victimization scales at T1 (.93 and 1.27 , respectively) was chosen as a cutoff point both for T1 and for T2 data, in order to avoid biases due to different distributions. Thus, we created the following categories: bully (scoring above .93 on the bullying scale and below 1.27 on the victimization scale), victim (scoring above 1.27 on the victimization scale and below .93 on the bullying scale), bully/victim (scoring above .93 and 1.27 on bullying and victimization scales, respectively), and not involved (all the rest). We also found prevalence figures for the 70th, 75th, and 80th percentile, as there is as yet no 'gold standard' for assigning the subjects. The results were comparable, with one notable exception: the number of bully/victims increased considerably with the lowering of the cutoff score, while the differences for bullies and victims were quite small. Thus, our method selects bullies and victims who answer to strict criteria and who are better differentiated from the bully/victims. Moreover, the 85th percentile score is in line with the cutoff score used by Perry et al. (1988) when they linked aggression and victimization (at the nominal level) to rejection.

The Reactive and Proactive Questionnaire (RePro). The RePro was developed by Dodge and Coie (1987). The original questionnaire consists of 12 aggressive behavior items for reactive (e.g. 'When teased, strikes back') and proactive (e.g. 'Threatens and bullies others') aggression, plus 12 filler items.

It was completed by teachers, who are usually well trained in assessing the behavior of the children in their care. Moreover, they spend a lot of time with children and they are likely to be objective. It was administered only at T2 and 11 of the original 12 items were employed. The answer modality was a 7-point scale, instead of a 5point scale as in the original version. The factor analysis (PCA with varimax rotation) yielded two factors, as expected, which explained $81.1 \%$ of the total variance. One item was deleted because of low loading. The loadings of the remaining items ranged from .62 to .87 for reactive aggression (four items) and from .65 to .87 for proactive 
aggression (six items). The reliabilities of the two scales were .93 and .95 respectively. We made use of standardized scores within each class. The correlation between reactive and proactive aggression was $.87(p<.01)$.

In order to check the incidence of the two types of aggression in the whole sample, the classification procedure employed by Dodge, Lochman, Harnish, Bates and Pettit (1997) was used. Reactively aggressive children scored more than $1 S D$ above the mean on the respective scale and below $1 S D$ above the mean on the proactive aggression scale. Proactively aggressive children received a proactive aggression score higher than $1 S D$ above the mean and a reactive aggression score lower than $1 S D$ above the mean. Children who received a reactive and a proactive aggression score higher than $1 S D$ above the mean on both scales were considered pervasively aggressive. All the others were classified as nonaggressive. We found 11 reactively aggressive children $(4.5 \%)$ and 10 proactively aggressive children (4.1\%). The pervasively aggressive children were more frequent $(33,13.6 \%)$. There were 188 (77.7\%) nonaggressive children.

\section{Results}

\section{Incidence of Bullying and Victimization}

Table 1 shows the percentages and the frequencies of the children in each role played at $\mathrm{T} 1$ and $\mathrm{T} 2$ (nominal scores). At T1, a total of $25.8 \%$ children were classified as bullies, bully/victims or victims. At T2 these figures were $15.7 \%$, which points to a decrease from T1 to T2 (McNemar's $\chi^{2}=5.11 ; p<.05$ ). The means and the standard deviations (among parentheses) of the raw scores of the continuous bullying and victimization scales were $5.76(7.38)$ and 7.83 (7.76) at T1, and $4.91(9.75)$ and 5.84 (10.69) at T2 respectively. These continuous scale scores also indicate a decrease, but a t-test for paired samples showed that only victimization decreased significantly $(t$ $(214)=3.08 ; p<.01)$.

We also checked whether our measures were related to gender. The t-test for independent variables showed that boys had higher scores on bullying, both at T1 $(t=-2.11 ; p<.05)$ and at T2 $(t=-2.00 ; p<.05)$. No significant results were found for the victimization scales.

Table 1. Percentages and Raw Frequencies (Among Parentheses) of the Participants in Each Role of the AVS at T1 and T2: Whole Sample and Subjects Present at Both Points in Time

\begin{tabular}{|c|c|c|c|c|}
\hline & \multicolumn{2}{|c|}{ Whole Sample } & \multicolumn{2}{|c|}{ Stable Participants } \\
\hline & $\begin{array}{c}\text { T1 } \\
\%(n)\end{array}$ & $\begin{array}{c}\mathrm{T} 2 \\
\%(\mathrm{n})\end{array}$ & $\begin{array}{c}\mathrm{T} 1 \\
\%(\mathrm{n})\end{array}$ & $\begin{array}{c}\mathrm{T} 2 \\
\%(\mathrm{n})\end{array}$ \\
\hline Bully & $9.7(23)$ & $7.4(18)$ & $9.3(20)$ & $7.4(16)$ \\
\hline Victim & $8.5(20)$ & $5.4(13)$ & $8.4(18)$ & $5.1(11)$ \\
\hline Bully/victim & $7.6(18)$ & $2.9(7)$ & $5.1(11)$ & $2.8(6)$ \\
\hline Not involved & $74.2(175)$ & $84.3(204)$ & $77.2(166)$ & $84.7(182)$ \\
\hline Total & $100(236)$ & $100(242)$ & \multicolumn{2}{|c|}{$100(215)$} \\
\hline
\end{tabular}


Table 2. Correlations of Bullying and Victimization at Two Points in Time

\begin{tabular}{lccc}
\hline & Bully T1 & Victim T1 & Bully T2 \\
\hline Victim T1 & $.56^{* *}$ & & \\
Bully T2 & $.69^{* *}$ & $.35^{* *}$ & \\
Victim T2 & $.42^{* *}$ & $.54^{* *}$ & $.59^{* *}$ \\
\hline
\end{tabular}

Note: $N=215$.

** Correlation is significant at the 0.01 level (2-tailed).

\section{Stability of Bullying and Victimization}

The stability of bullying and victimization between $\mathrm{T} 1$ and $\mathrm{T} 2$ was investigated by means of correlations and cross-tabulations. Only the children present at both points in time were used. Table 2 shows the correlations and the coefficients in italics indicate a moderate degree of stability of bullying and victimization over a period of one year. The comparison between the coefficient for bullying with that for victimization (Fisher's $\mathrm{Z}$ transformation) showed bullying being more stable than victimization $(Z=2.99 ; p<.01)$.

Bullying and victimization were also related to each other. This indicates that these roles are not yet clearly defined, and that some of those who bully are sometimes also victims.

Cross-tabulations employed nominal scores (Kappa $=.36 ; p<.001)$. Results showed that $40 \%(n=8)$ of the children who were labeled as bullies at T1 were still bullies at T2 (50\% of the bullies at T2 were also bullies at T1). Among the victims, $16.7 \%$ $(n=3)$ were still victims at T2 $(27.3 \%$ were already victims at $\mathrm{T} 1)$, while $54.5 \%(n=$ 6) of bully/victims remained in this role from $\mathrm{T} 1$ to $\mathrm{T} 2(100 \%$ of the bully/victims at $\mathrm{T} 2$ were bully/victims at T1). These figures pointed to considerable stability, particularly in the bully role and the bully/victim role over a period of one year. Among those children who changed their role, 30 (68.2\%) improved their status-from being involved they became uninvolved - while 14 (31.8\%) were uninvolved at T1, but became involved at T2. Only two children remained involved at both points in time, and switched from the status of bully/victim to those of bully and victim.

In order to investigate if boys and girls differed in stability of involvement, the correlations were run for the two sexes separately. Boys had higher coefficients than girls, both in bullying ( $r=.72$ for the boys versus $r=.63$ for the girls) and victimization ( $r=.72$ for the boys versus $r=.41$ for the girls). The difference between the sexes (Fisher's $\mathrm{Z}$ transformation) was significant only for victimization $(t=3.42 ; p<.001)$.

\section{Relationship of Bullying and Victimization to Different Types of Aggression}

Two hierarchical regression analyses were run to investigate the link between bullying and victimization and reactive and proactive aggression (as the RePro was only available at T2, only data collected at this point in time were analysed). Gender was entered in the first step, the two scores for reactive and proactive aggression in the second, and the interactions between these and gender in the third (the last two entered 
Table 3. Hierarchical Regression Analyses of the RePro on the AVS

\begin{tabular}{|c|c|c|c|c|c|c|c|}
\hline Dep.Var. & Predictors & $B$ & $\beta$ & $R$ & $R^{2}$ & $\Delta R^{2}$ & $F(d f)$ \\
\hline \multicolumn{8}{|l|}{ Bully } \\
\hline \multirow[t]{2}{*}{ I step } & & & & .16 & .03 & & $4.85(1)^{*}$ \\
\hline & Gender & -.14 & $-.16^{*}$ & & & & \\
\hline \multirow[t]{3}{*}{ II step } & Gender & 00 & & .57 & .32 & .29 & $37.22(3)^{* * *}$ \\
\hline & Reactive & .29 & $.33 * *$ & & & & \\
\hline & Proactive & .24 & $.27 *$ & & & & \\
\hline \multirow{5}{*}{ III step } & & & & .58 & .33 & .01 & $29.58(4)^{* * *}$ \\
\hline & Gender & .00 & .02 & & & & \\
\hline & Reactive & .27 & $.30^{* *}$ & & & & \\
\hline & Proactive & .24 & $.27 * *$ & & & & \\
\hline & Gender*reactive & -.11 & $-.12 *$ & & & & \\
\hline \multirow{3}{*}{$\begin{array}{l}\text { Victim } \\
\text { I step }\end{array}$} & & & & & & & \\
\hline & & & & .11 & .01 & & n.s. \\
\hline & Gender & -.10 & -.11 & & & & \\
\hline \multirow{3}{*}{ II step } & & & & .42 & .17 & .16 & $24.97(2)^{* * *}$ \\
\hline & Gender & .00 & .03 & & & & \\
\hline & Reactive & .39 & $.42 * * *$ & & & & \\
\hline
\end{tabular}

Note: $N=242$.

$* p<.05 ; * * p<.01 ; * * * p<.001$.

with the stepwise method). Dependent variables were the bullying and victimization continuous scales of the AVS.

Since reactive and proactive aggression were highly correlated $(r>.80)$, we had to cope with collinearity problems. Tabachnick and Fidell (1996, p. 87) fixed the criteria for multicollinearity in a 'conditioning index greater than 30 and at least two variance proportions higher than .50 for a given root number'. Although in our results two variance proportions were greater than .50 , the conditioning index was much lower than 30 . Thus, even if the risk of collinearity was pretty high, we cannot demonstrate that this was the case in our sample.

The scores of the dependent variables revealed some extreme cases. Thus, we ran our regression analyses on both the untreated scores and the scores after they had been normalized with the SPSS ranking program. We obtained similar results with both methods, except that when we used the untreated scores, victimization was more strongly linked to proactive aggression (not expected), while with the ranking procedure it was linked to reactive aggression (as expected). Table 3 shows the results of the regressions obtained with the ranking procedure (in order to center the variable gender as well, it was recoded into the values of -1 and +1 for boys and girls, respectively).

In general, the results support the expectation that proactive and reactive aggression are both associated with bullying, while reactive aggression is associated with 
Table 4. Cross-tabulation Between Type of Aggression and Involvement in Bullying: Observed and (Between Parentheses) Expected Frequencies

\begin{tabular}{lllcc}
\hline & Proactive & Reactive & Proactive-reactive & Nonaggressive \\
\hline Bully & $2(.7)^{\dagger}$ & $1(.8)$ & $9(2.5)^{* * *}$ & $6(14.0)^{* * *}$ \\
Victim & $0(.5)$ & $2(.6)^{*}$ & $2(1.8)$ & $9(10.1)$ \\
Bully-victim & $1(.3)^{\dagger}$ & $1(.3)^{\dagger}$ & $5(1.0)^{* * *}$ & $0(5.4)^{* * *}$ \\
Not involved & $7(8.4)^{\dagger}$ & $7(9.3)^{*}$ & $17(27.8)^{* * *}$ & $173(158.5)^{* * *}$ \\
\hline
\end{tabular}

Note: $N=242$.

${ }^{\dagger} p<.10 ; * p<.05 ; * * * p<.001$.

victimization. An interaction effect of gender and reactive aggression revealed that reactively aggressive boys were more often bullies, but reactively aggressive girls were not. No other interaction effects involving gender were found. However, a t-test on the reactive and proactive aggression scales with gender as a factor showed that boys obtained higher scores than girls (both $p$ 's $<.001$ ) on both scales.

The link between type of aggression and involvement in bullying was also demonstrated by means of cross-tabulation $(4 \times 4)$, employing the nominal scores of the AVS (bully, victim, bully/victim and not involved) and the RePro (proactively aggressive, reactively aggressive, pervasively aggressive and nonaggressive). The Fisher's exact test $(F=51.36 ; p<.001)$ showed the link to be statistically significant. Table 4 shows the observed and expected cell frequencies and the significant differences among them.

Bullies were slightly more proactively aggressive than expected by chance, while both bullies and bully/victims were overrepresented in the pervasively aggressive group, meaning that they were both reactively and proactively aggressive. Victims scored high only on reactive aggression. Nonaggressive children were underrepresented among the bullies and the bully/victims, while those not involved in the bullying situation were definitely nonaggressive.

In order to investigate whether stability of involvement in bullying was linked to different types of aggression, again we selected the 215 children stably present throughout the study. Thus, stable bullies $(n=8)$, stable victims $(n=3)$ and stable bully/victims $(n=6)$ were compared with the unstable ones (20 one-time bullies, 23 one-time victims, five one-time bully/victims) by means of t-tests. No significant results were found when stable bullies were compared with unstable bullies, although the former scored higher on both reactive and proactive aggression. Stable victims were both more reactively and proactively aggressive than unstable victims $(t=3.58$; $p<.01$ and $t=3.47 ; p<.01$, respectively). Finally, stable bully/victims turned out to be more reactively aggressive $(t=2.53 ; p<.05)$ than the unstable ones.

\section{Discussion}

The outcomes of the study met our expectations. In fact, bullying was positively linked with both reactive and proactive aggression, while victimization was associated only with reactive aggression. This was borne out using both continuous scale scores and 
nominal classifications. Bully/victims scored high on both types of aggression. The outcomes of the comparisons between the stable bullies, victims, bully/victims and the unstable ones were less supportive of our hypothesis. There may be a number of reasons for this. First, the number of participants involved is small, making the power of the comparisons low. Second, stability was based on playing the same role at only two points in time versus one point in time (unstable). It is still possible that those involved in one specific role at two points in time change status as they grow older and develop. Thus, more measurements during a longer period may be required to assess stability.

We would surmise that proactive aggression in particular is responsible for bullying behavior, as bullies must expect advantages from it. They have their role to defend and they use it to dominate the others. Then, once they are labeled as aggressive, it may be difficult to change their behavior. Pulkkinen (1996) claims that both types of aggression may be present in bullies. According to her, there are individuals who act proactively and defend themselves if provoked and there are those who react aggressively if attacked, but who never attack first. Thus, we might expect that exclusively proactively aggressive children are rare, while those who are both are more common. There is in fact some support for this interpretation in our data, as we found that children who displayed both types of aggression were definitely more numerous than the others. Similar outcomes have also been found by Dodge and Coie (1987) and by Dodge et al. (1997). Also bully/victims display both types of aggression, because, being both the target and the perpetrators of the bullying, they are reactively aggressive in response to attack by others, but also proactively aggressive in initiating bullying. This group has been often reported as hostile and extremely aggressive, in many different ways (Olweus, 1993; Pellegrini et al., 1999; Salmivalli \& Nieminen, 2002). Victims, on the other hand, may be exasperated by continuous harassment and tend to show their anger and aggressivity. Most of the time, this fails to stop others' bullying, and it may even have the effect of making the bully more ruthless.

As such, the finding that bullies and bully/victims are both reactively and proactively aggressive and that victims are reactively aggressive would appear to be a robust result. Moreover, it has repeatedly been found in the literature that correlations tend to be higher when the same source has been used to collect data on two issues. Here, we used two different sources (i.e. teachers on type of aggression, and pupils on involvement in bullying) and the use of different informants usually leads to lower bound estimates of the real correlation. Unfortunately, our data also show-as has been shown on many other occasions (Dodge \& Coie, 1987; Dodge et al., 1997; Pulkkinen, 1996) - that reactive and proactive aggression are highly correlated. One reason may be that in order to become proactively aggressive a child must already have developed a tendency to respond with reactive aggression. In other words, proactive aggression could be a type of aggression that develops only in addition to reactive aggression. Dodge and Coie (1987) also suggested that a measurement bias might play a role, as teachers may have difficulties in distinguishing the two behaviors. In fact, they often observe the final part of the aggressive interactions and not all the sequences that lead up to them. Thus, they may merge all aggression episodes into one broader category. The authors believe that teachers could be trained in observing and reporting such differences between types of aggression. The teachers in our study did not receive any training to assess the two types of aggression. It might also be feasible to develop such a measure for children, who presumably will often be witnesses to the full sequence of aggressive interactions between peers. However, Salmivalli and 
Nieminen (2002), found that the association between reactive and proactive aggression did not depend on informants.

As to stability of involvement, both bullying and victimization were stable, although the general involvement in bullying decreased with age. Tremblay (2000) suggested that parallel to the developmental decrease in aggression, direct bullying may also decrease, perhaps giving way to more indirect forms of bullying. In our sample bullying turned out to be more persistent than victimization, which significantly decreased (Boulton \& Underwood, 1992; Olweus, 1991; Salmivalli et al., 1998). A number of explanations can be offered. Bullies may persist in their role because they obtain advantage from it, or because they are reinforced in that role by the expectations of their peers and by the reputation they have built up. Moreover, being victimized is likely to be accompanied by strong, unpleasant feelings, and these may powerfully motivate victims to change their ways. Smith et al. (1999) suggested the following reasons for the decrease in victimization. First, younger children have more children older than them who can bully them. Second, younger children are less socially competent. Third, younger children use a different (wider) definition of bullying. However, there are still pupils who remain in their victim role, at least over a one-year interval. As time passes they are increasingly victimized, once they have been labeled a scapegoat.

Boys were more stable than girls in victimization, presumably because these boys tended to respond with reactive aggression to provocation (Kochenderfer \& Ladd, 1997). Girls are usually protected more than boys by their exclusive friends (Boulton $\&$ Smith, 1994) or by teachers (Kumpulainen et al., 1999).

Finally, the study provides for an omission. There is a dearth of prevalence figures in The Netherlands based on data other than self-reports. The AVS is a reliable peer report measure. The results indicated that the frequency of bullying was about the same as reported by Bokhorst et al. (2000), but that the frequency of victimization was lower. These differences could have come about because bully/victims reported themselves as victims and not as bullies, which they also were. Haselager (1997) and Mooij (1992), whose subjects were older, found percentages very much like ours. Boys tend more often to be bullies. Similar results have been reported by Bokhorst et al. (2000) and throughout the literature (Boulton \& Underwood, 1992; Kochenderfer \& Ladd, 1996b; Lagerspetz et al., 1982; Olweus, 1993; Whitney \& Smith, 1993). It may be that bullying has a higher social status among boys, because it is considered as a way of proving themselves in the eyes of others ('tough boys'). Boys are expected to behave in a rough way in order to be accepted by the peer group (Salmivalli et al., 1996). Girls, on the other hand, are usually brought up to be polite, obedient and nice; they also develop an empathic ability (Erwin, 1993). Moreover, girls prefer dyadic interactions based on intimacy, while boys' friendships tend to be more concerned with power and excitement (Boulton, 1999). Alternatively, the operationalizations used in this study asked for direct ways of bullying, and this may not be the best instrument to unearth bullying by girls, which is assumed to be more indirect (Crick \& Bigbee, 1998). No gender differences were found for victimization.

This study is limited because it concerns only a one-year period with two measurements across separate school years. The moderate stabilities found in this study and the meaningful differences between children stably and unstably involved in bullying suggest that longitudinal studies with more than two measurement points may be fruitfully used to investigate developmental pathways of involvement in bullying (cf. Loeber \& LeBlanc, 1990). 
Nevertheless, we believe that finding a link between bullying and proactive aggression may be very important, because it is at the very least possible that both phenomena derive from similar underlying processes (e.g., deficits in social information processing; Crick \& Dodge, 1994, 1996). If this is the case, programs to intervene in proactive aggression problems might be used for a double purpose: reducing aggression as well as reducing bullying in schools. Dodge et al. (1997) claimed that reactive aggression may be more resistant to treatment than proactive aggression, but recently programs have been developed to deal specifically with reactive aggression as well (Graham, Hudley, \& Williams, 1992; Hudley \& Graham, 1993). Studies of underlying processes as well as intervention studies will be informative about the causal nature of the links between types of involvement in bullying and types of aggression.

\section{References}

Björkqvist, K., Lagerspetz, K. M. J., \& Kaukiainen, A. (1992). Do girls manipulate and boys fight? Development trends in regard to direct and indirect aggression. Aggressive Behavior, $18,117-127$.

Bokhorst, J., Goossens, F. A., Dekker, P., \& De Ruyter, P. (2000). Predictoren van betrokkenheid bij pesten in de middenbouw van het basisonderwijs [Predictors of involvement in bullying in the middle years of elementary school]. Tijdschrift voor Orthopedagogiek, 37, $372-383$.

Boulton, M. J. (1999). Concurrent and longitudinal relations between children's playground behavior and social preference, victimization, and bullying. Child Development, 70, 944-954.

Boulton, M. J. \& Smith, P. K. (1994). Bully/victim problems among middle school children: Stability, self-perceived competence, peer perception and peer acceptance. British Journal of Developmental Psychology, 12, 315-329.

Boulton, M. J. \& Underwood, K. (1992). Bully/victim problems among middle school children. British Journal of Educational Psychology, 62, 73-87.

Crick, N. R. \& Bigbee, M. A. (1998). Relational and overt forms of peer victimization: a multiinformant approach. Journal of Consulting and Clinical Psychology, 66, 337-347.

Crick, N. R. \& Dodge, K. A. (1994). A review and reformulation of Social Information Processing mechanisms in children's social adjustment. Psychological Bulletin, 115, 74-101.

Crick, N. R. \& Dodge, K. A. (1996). Social information-processing mechanisms in reactive and proactive aggression. Child Development, 67, 993-1002.

Crick, N. R. \& Dodge, K. A. (1999). Superiority in the eye of the beholder: a comment on Sutton, Smith and Swettenham. Social Development, 8, 128-131.

Crick, N. R. \& Grotpeter, J. K. (1995). Relational aggression, gender, and social-psychological adjustment. Child Development, 66, 710-722.

Dodge, K. A. (1991). The structure and function of reactive and proactive aggression. In D. J. Pepler \& K. H. Rubin (Eds.), The development and treatment of childhood aggression (pp. 201-218). Hillsdale, NJ: Lawrence Erlbaum.

Dodge, K. A. \& Coie, J. D. (1987). Social information-processing factors in reactive and proactive aggression in children's playgroups. Journal of Personality and Social Psychology, 53, $1146-1158$.

Dodge, K. A., Lochman, J. E., Harnish, J. D., Bates, J. E., \& Pettit, G. S. (1997). Reactive and proactive aggression in school children and psychiatrically impaired chronically assaultive youth. Journal of Abnormal Psychology, 106 (1), 37-51.

Erwin, P. (1993). Friendship and peer relations in children. Chichester: John Wiley and Sons.

Gilmartin, B. G. (1987). Shyness \& love: Causes, consequences, and treatment. Lanham, MD: University Press of America.

Graham, S., Hudley, C., \& Williams, E. (1992). Attributional and emotional determinants of aggression in African-American and Latino early adolescents. Developmental Psychology, $28,731-740$.

Haselager, G. (1997). Classmates. Studies on the development of their relationships and personality in middle childhood. Unpublished doctoral dissertation, University of Nijmegen, The Netherlands. 


\section{Marina Camodeca et al.}

Hawker, D. S. J. \& Boulton, M. J. (2000). Twenty years' research on peer victimization and psychosocial maladjustment: A meta-analytic review of cross-sectional studies. Journal of Child Psychology and Psychiatry, 41, 441-455.

Hudley, C. \& Graham, S. (1993). An attributional intervention to reduce peer-directed aggression among African-American boys. Child Development, 64, 124-138.

Kochenderfer, B. J. \& Ladd, G. W. (1996a). Peer victimization: Cause or consequence of school maladjustment. Child Development, 67, 1293-1305.

Kochenderfer, B. J. \& Ladd, G. W. (1996b). Peer victimization: Manifestations and relations to school adjustment in kindergarten. Journal of School Psychology, 34, 267283.

Kochenderfer, B. J. \& Ladd, G. W. (1997). Victimized children's responses to peers' aggression: Behaviors associated with reduced versus continued victimization. Development and Psychopathology, 9, 59-73.

Kumpulainen, K., Räsänen, E., \& Henttonen, I. (1999). Children involved in bullying: psychological disturbance and the persistence of the involvement. Child Abuse and Neglect, 23, $1253-1262$.

Lagerspetz, K. M., Björkqvist, K., Berts, M., \& King, E. (1982). Group aggression among school children in three schools. Scandinavian Journal of Psychology, 23, 45-52.

Loeber, R. \& Dishion, T. (1983). Early predictors of male delinquency: A review. Psychological Bulletin, 94, 69-99.

Loeber, R. \& LeBlanc, M. (1990). Toward a developmental criminology. In M. Tonry \& N. Morris (Eds.), Crime and justice: A review of research (Vol. 12, pp. 375-473). Chicago, Il: University of Chicago Press.

Mooij, T. (1992). Pesten in het onderwijs [Bullying at school]. Instituut voor Toegepaste Sociale Wetenschappen, Nijmegen, The Netherlands.

Olweus, D. (1979). Stability of aggressive reaction patterns in males: a review. Psychological Bulletin, 86, 852-875.

Olweus, D. (1989). The Bully/Victim Questionnaire. Norway: University of Bergen.

Olweus, D. (1991). Bully/victim problems among schoolchildren: Basic facts and effects of a school-based intervention program. In D. Pepler \& K. H. Rubin (Eds.), The development and treatment of childhood aggression. Hillsdale, NJ: Lawrence Erlbaum.

Olweus, D. (1993). Bullying at school. What we know and what we can do. Oxford: Blackwell.

Pellegrini, A. D., Bartini, M., \& Brooks, F. (1999). School bullies, victims and aggressive victims: Factors relating to group affiliation and victimization in early adolescence. Journal of Educational Psychology, 91, 216-224.

Perry, D. G., Kusel, S. J., \& Perry, L. C. (1988). Victims of peer aggression. Developmental Psychology, 24, 807-814.

Price, J. M. \& Dodge, K. A. (1989). Reactive and proactive aggression in childhood: Relations to peer status and social context dimensions. Journal of Abnormal Child Psychology, 17, 455-471.

Pulkkinen, L. (1996). Proactive and reactive aggression in early adolescence as precursors to anti and prosocial behavior in young adults. Aggressive Behavior, 22, 241-257.

Pulkkinen, L. \& Pitkänen, T. (1993). Continuities in aggressive behavior from childhood to adulthood. Aggressive Behavior, 19, 249-263.

Rigby, K., Black, G., \& Wish, A. (1994). Implications of school children's peer relations for wife abuse in Australia. Criminology Australia, August, 8-12.

Salmivalli, C. \& Nieminen, E. (2002). Proactive and reactive aggression among school bullies, victims and bully-victims. Aggressive Behavior, 28, 30-44.

Salmivalli, C., Lappalainen, M., \& Lagerspetz, K. M. J. (1998). Stability and change of behavior in connection with bullying in schools: A two-year follow-up. Aggressive Behavior, 24, $205-218$.

Salmivalli, C., Lagerspetz, K., Björkqvist, K., Österman, K., \& Kaukiainen, A. (1996). Bullying as a group process: Participant roles and their relations to social status within the group. Aggressive Behavior, 22, 1-15.

Schwartz, D., McFayden-Ketchum, S. A., Dodge, K. A., Pettit, G. S., \& Bates, J. E. (1998). Peer group victimization as a predictor of children's behavior problems at home and in school. Development and Psychopathology, 10, 87-99. 
Smith, P. K., Madsen, K. C., \& Moody, J. C. (1999). What causes the age decline in reports of being bullied at school? Towards a developmental analysis of risks of being bullied. Educational Research, 41, 267-285.

Sourander, A., Helstelä, L., Helenius, H., \& Piha, J. (2000). Persistence of bullying from childhood to adolescence: A longitudinal 8-year follow-up study. Child Abuse and Neglect, 24, 873-881.

Tabachnick, B. G. \& Fidell, L. S. (1996). Using multivariate statistics (3rd edn). New York: HarperCollins.

Tremblay, R. E. (2000). The development of aggressive behavior during childhood: What have we learned in the past? International Journal of Behavioral Development, 24, 129-141.

Whitney, I. \& Smith, P. K. (1993). A survey of the nature and extent of bullying in junior/middle and secondary schools. Educational Research, 35, 3-25.

Wiggins, J. S. \& Winder, C. L. (1961). The Peer Nomination Inventory. An empirically derived sociometric measure of adjustment in pre-adolescent boys. Psychological Report, 9, 643-677.

\section{Acknowledgment}

We would like to thank Peter Dekker for his statistical advice, and anonymous reviewers for their comments on an earlier draft of this paper. 